\title{
PEMBERDAYAAN LOKALITAS DAN KREATIVITAS: UPAYA MENUJU BANDUNG KOTA KREATIF
}

\author{
Tri Rahayu ${ }^{1}$, Roni Sugiarto ${ }^{2}$ \\ 1. Kelompok Bidang Ilmu Filsafat Arsitektur, Program Studi Ilmu Filsafat, Fakultas Filsafat, \\ Universitas Katolik Parahyangan, Jl. Nias No.2 Bandung \\ 2. Kelompok Bidang Ilmu Sejarah Teori dan Falsafah Arsitektur, Program Studi Teknik \\ Arsitektur, Fakultas Teknik, Universitas Katolik Parahyangan, Jl. Ciumbuleuit No. 94 Bandung \\ archde14@gmail.com, ronisugiarto1304@gmail.com
}

\begin{abstract}
Abstrak
Ketika modernitas dengan segala kebakuan dan kepraktisannya kian merayap, lokalitas pun tetap elegan dengan pesonanya. Lokalitas seolah menjadi daya pikat tersendiri, menjadi obat kerinduan pada masa lalu. Segala yang berbau tradisi, menginspirasi arsitek dan perancang kota. Rancangan yang kreatif tentu memiliki daya pikat tersendiri bagi warga dan wisatawan lokal ataupun nonlokal. Bandung adalah kota dengan julukan Paris Van Java, yang berkonsekuensi pada penataan infrastruktur dan wajah kota yang kental identitasnya dengan budaya Sunda nan elok. Peluang ini tentu membutuhkan kreativitas yang menjajakan keunikan dan identitas khas ala Bandung. Penelitian tentang penaataan ruang kota, strategi perencanaan menuju kota kreatif, dan strategi berkelanjutan tentu menjadi penting untuk mewujudkan Bandung Kota Kreatif. Penelitian dilakukan dengan mengamati infrastruktur kota Bandung di beberapa titik sentral pada bangunan bersejarah hingga wajah kota, dan bagaimana strategi pemerintah mengatasi persoalan ini, kaitannya dengan kreativitas. Hasil penelitian menunjukkan bahwa upaya menuju Bandung Kota Kreatif dilakukan melalui pemberdayaan 'ekonomi kreatif' di bidang fashion, kuliner, dan desain yang bertebaran menghiasi wajah kota hingga wilayah perbukitan. Kota kreatif memungkinkan pencapaian masyarakat hidup sejahtera dan mandiri secara ekonomi. Lebih jauh lagi, melalui program 'Bandung Kota Kreatif', imbasnya bukan hanya menuju kota kreatif tapi sebagai 'smart city'yang dilakukan melalui strategi : inovasi, desentralisasi dan kolaborasi.
\end{abstract}

Kata kunci:lokalitas, kreativitas, budaya Sunda, Bandung kota kreatif

\begin{abstract}
Title: Empowerment of Locality and Creativity: The Effect towards Bandung Creative City

As modernity with all rigidity and practically increasingly creeping, the locality was still elegant with its charm. Localities seems to be a special allure which become healer of longing of the past. Everything related to tradition inspires architects and city planners. Creative design certainly has allure for residents, local and non local tourists. Bandung is the city wellknown as Paris Van Java, which has consequence to the arrangement of the infrastucture and face of the city with strong identity of exquisite Sundanese culture. These opportunities would require creativity which offer uniqueness and special identity of Bandung. The study of city arrangement, planning stategy towards creative city, and sustainable strategy would be essential to realize the Bandung Creative City. The study was conducted by observing Bandung infrastucture at some central points in the heritage building until face of the city, and how the goverment's strategy to overcome this problem, related to creativity. The result shows that efforts to Bandung Creative City is done through empowerment of 'creative economy' in fashion, culinary, and design decorate city faces up to hilly region. Creative city allows the achivement of community prosperity and economically independence. Furthermore, through 'Bandung Creative City' program, the impact is not only to the creative city but also to a 'smart city' which is done the following strategies: innovation, decentralization, and collaboration.
\end{abstract}

Keywords: locality, creativity, Sundanese culture, Bandung creative city 


\section{Pendahuluan}

Lokalitas dan kreativitas merupakan identitas yang melekat pada akhir modernisme. Segala yang berbau tradisi seolah kian menawan ketika keseragaman bentuk polatik terasa membosankan. Bukan saja pada hunian rumah tinggal yang mengambil inspirasi budaya tradisi, melainkan juga pada skala yang lebih besar pada tata kota juga mengindikasikan hal serupa. Para arsitek dan perancang kota dituntut lebih kreatif menyiasati tuntutan dan kebutuhan masyarakat urban. Rupanya ini menjadi indikasi kuat ketika para perancang mulai melirik rancangan ala Sunda tradisi pada tempat-tempat wisata, kuliner hingga fashion. Disaat kerinduan pada tradisi menjadi asupan nutrisi yang menenangkan, pada arsitek dan perancang kota melihatnya sebagai peluang kreativitas dalam perancangan infrastruktur kota yang mengadopsi budaya tradisi. Julukan Bandung Paris Van Java sekaligus menjadi daya pikat tersendiri bagi wisatawan lokal maupun non lokal. Peluang ini menjadi isyarat utama perancangan yang mengolah kultur modern bergandengan dengan tradisi. Disisi lain, karakter masyarakat Sunda yang memiliki kebiasaan 'ngariung' (dari bahasa Sunda yang artinya 'berkumpul') sekaligus menjadi peluang kreativitas yang perlu diperhatikan dalam mewujudkan Bandung Kota Kreatif dan Smart City. Kondisi yang demikian dapat menjadi peluang sekaligus tantangan dalam pengembangan kota kreatif.

Sebutan tentang 'Kota Kreatif' tentu bukan s+emata karena banyaknya seni dan kerajinan yang ada, juga bukan sebatas kreativitas masyarakatnya semata, melainkan juga penataan ruang kota, dan tersedianya fasos fasum yang memadai. Istilah kota kreatif, rupanya telah banyak mengundang minat para akademisi dan pemangku kebijakan (Girard, L.F., Baycan, T., Nijkamp, 2011). Dari yang mengkonsentrasikan kajiannya pada upaya pemberdayaan industri kreatif dilihat dari konteks kemodernan (Girard., et.all, 2011) hingga yang mencoba mengkritisi dan merekonseptualisasi ulang model kota kreatif (Harris,A., Mareno, L., 2011). Sementara itu kajian tentang lokalitas sebagai salah satu peluang pengembangan kota kreatif masih banyak yang belum tergali. Padahal banyak hal yang bisa dilakukan untuk menciptakan keunikan kota. Itu sebabnya, penelitian lokalitas dan kreativitas sebagai kesatuan pemberdayaan menuju kota kreatif, kiranya layak untuk dilihat dan dikaji lebih jauh. Fokus penelitian mencoba mencari berbagai aspek upaya mewujudkan kota kreatif di Bandung. Bagaimana penataan ruang kota? Strategi seperti apa yang dilakukan pemerintah sebagai upaya perencanaan menuju kota kreatif? Peran apa yang dapat dilakukan masyarakat untuk mendukung program pemerintah? Serta bagaimana strategi berkelanjutan yang dilakukan pemerintah untuk mewujudkan Bandung sebagai kota kreatif?

\section{Metode Penelitian}

Penelitian ini dilakukan melalui pendekatan yang bersifat kualitatif (qualitative method), dengan teknik pengambilan data observasi langsung (direct observation). Peneliti terlibat secara langsung (insider)di lapangan; mengalami ruang, mengamati dan meleburkan diri dengan fenomena yang terjadi. Hal ini dilakukan untuk menemukan data lebih detail sehingga memungkinkan peneliti dapat mengabstraksi pengetahuan baru dari 
proses, tindakan, dan interaksi langsung dengan objek yang ditelitinya, seperti yang dikatakan oleh Creswell (2008).

\section{Metode Pengumpulan Data}

Pengamatan langsung di lapangan dilakukan pada hari Sabtu tanggal 6 dan 13 Agustus 2016, kemudian di hari Minggu tanggal 7, 14 dan 21 Agustus 2016. Di hari Sabtu, peneliti mengalami ruang dan mengamati kawasan di sepanjang Jl. Merdeka, yang meliputi lokasi tempat berdirinya Gedung Merdeka, Museum Konferensi Asia Afrika, dan Alun-alun pusat Kota Bandung. Perjalanan diteruskan dengan mengamati situasi yang terjadi di sekitar Jl. Braga, sebagai kota tua dan tempat bangunan-bangunan Heritage di Kota Badung. Pada hari berikutnya, di hari Minggu tanggal 7 Agustus 2016 peneliti memfokuskan pencarian data di daerah Gedung Sate dan di kawasan Dago pukul 06.00-10.00 WIB untuk menangkap moment car free day. Peneliti menyusuri jalan dengan menjadi bagian masyarakat yang menikmati ruang bebas dari $\mathrm{Jl}$. Cikapayang menuju Jl. Ir Juanda hingga acara selesai. Pencarian data dilakukan kembali di hari Minggu tanggal 14 Agustus 2016, untuk mendapatkan situasi yang berbeda di sepanjang daerah Dago pada moment car free day. Tanggal 21 Agustus peneliti melakukan pengamatan khusus di Kampung Kreatif yang terletak di Dago Pojok.

Penentuan lokasi pengambilan data di daerah Dago, karena daerah tersebut merupakan wajah kota Bandung yang banyak dipadati Factory Outlet, tempat kuliner, serta adanya kampung kreatif di jantung kota. Selain itu penelitian juga dilakukan di daerah perbukitan Lembang sebagai tempat favorit masyarakat untuk menghabiskan waktu
weekend.Tempat yang dipilih adalah Dusun Bambu di Lembang. Tempat tersebut dijadikan sampel penelitian karena selain konsep perancangan arsitekturnya yang mengadopsi lokalitas budaya Sunda, juga tempat tersebut merupakan tempat yang banyak diminati oleh wisatawan lokal ataupun non lokal.

Pengambilan data dilakukan peneliti dengan cara: mengalami fenomena yang terjadi dan mengambil objek foto yang mewakili situasi di beberapa titik penting kota Bandung sebagai kota kreatif-mulai dari kawasan heritage yang terletak di Jl. Merdeka dan Jl. Braga, kawasan wajah kota yang terletak di J1. Ir. Juanda dan Jl. Dago Pojok hingga kawasan perbukitan yang mengusung konsep lokalitas Sunda yang terletak di Jl. Kolonel Matsuri Lembang. Dengan demikian, data yang diperoleh dapat memberikan gambaran lebih detail dan dapat mewakili pengembangan kota kreatif di Bandung.

\section{Metode Analisis}

Penelitian ini menggunakan analisis melalui pendekatan metode fenomenologi dan analisis teks. Metode fenomenologi digunakan untuk menyelami dan memahami fenomena yang terjadi di spot-spot kawasan heritage, wajah kota hingga kawasan perbukitan Bandung. Fenomenologi merupakan pendekatan filsafat yang memungkinkan terjadinya relasi esensial antara peneliti/subjek yang berkesadaran (conscious subject) dan objek (object). Fenomenologi juga memungkinkan penjelasan tentang objek bukan sekedar sebagai faktafakta melainkan juga menyelami esensinya. Dalam memahami sebuah objek-bangunan, kawasan, dan situasi yang terjadi-peneliti meleburkan diri tanpa jarak, sekaligus juga mengambil 
jarak dari definisi untuk mendapatkan berbagai kemungkinan lain yang lebih terbuka.

Sementara analisis teks digunakan untuk mendeskripsikan pengalaman keterleburan langsung peneliti dengan objek tanpa jarak. Teks yang dimaksudkan bukan saja teks gramatikal-yang didapat dari internet berupa informasi seputar Bandungmelainkan juga teks berupa gambar yang diperoleh dari pengambilan foto di lapangan. Penggabungan antara metode fenomenologi dan analisis data teks dilakukan untuk mendapatkan hasil penelitian lebih terbuka, akurat dan komprehensif.

\section{Hasil dan Pembahasan}

Kreativitas telah menemukan banyak refleksi dalam studi perkotaan yang menawarkan beberapa konsep baru; seperti kelas kreatif, industri kreatif, lingkungan kreatif, dan kota kreatif (Girard, et.all, 2011).Wacana kota kreatif telah menjadi perbincangan hangat di kalangan akademisi dan praktisi yang bermuara pada konsepkonsep Florida (2002), Hall (1998 dan 2000), Scott (2000), Howkins (2002), Helbrecht (2004), ISoCaRP (2005), Wu (2005), Jones (2007), dan Musterd et.all (2007).Sejak ide Florida (2002) tentang kelas kreatif, industri kreatif dan kota kreatif juga ide Heilbrun., Gray (2004), Pratt (1997), Vogel (2001), Scott (2003), dan Gabe (2006) tentang keberhasilan lingkungan, maka tumbuh kesadaran baru tentang kegiatan-kegiatan kreatif. Kota kreatif, umumnya dipahami dan digunakan dalam empat cara: (1) sebagai titik fokus dari seni dan infrastruktur budaya, (2) sebagai tempat berkembangnya ekonomi kreatif, (3) kota kreatif identik dengan kelas kreatif, dan (4) sebagai tempat berkembangnya budaya kreatif (Girard., et al, 2011). Lebih jauh Girard mengatakan bahwa kota kreatif seharusnya mengembangkan solusi imajinatif dan inovatif untuk berbagai masalah sosial, ekonomi dan lingkungan.

Kota Bandung adalah kota dengan beragam komunitas dan identitas. Banyak pendatang dari luar kota, juga dari manca negara. Kondisi yang demikian menuntut adanya ruangruang komunal yang dapat memfasilitasi mereka untuk saling berinteraksi dan berdiskusi. Salah satu solusi imajinatif dan inovatif pemerintah kota sebagai bentuk konkret berkembangnya ekonomi kreatif yang mengakomodir beragam kebutuhan masyarakat kota adalah dengan mengosongkan ruang di sepanjang Jl. Ir. Djuanda di setiap hari minggu, lewat program "car free day. "Ruang bebas asap tersebut memungkinkan berbagai aktivitas dan beragam komunitas bertemu saling berinteraksi, berdagang, berkarya seni secara langsung, dan berdiskusi santai tanpa gangguan bisingnya suara kendaraan yang memadati ruang kota di setiap harinya.

Segar, sejuk, tanpa asap, dan terhubung dengan alam tanpa sekat segera terasa saat mengalami ruang terbuka hijau di sepanjang Jl. Ir. Juanda Dago di hari minggu. Melebur dalam ruang kota, dalam keriuhan orang-orang dan diantara pengguna sepeda yang membaur dengan pejalan kaki. Pengalaman hampir serupa juga terasa saat diri berada di ruang terbuka hijau daerah perbukitan Lembang, tepatnya di Dusun Bambu Family Leisure Park. Merasakan kesegaran dan aroma pohon pinus, menatap langit tanpa batas 
membuat diri menjadi bagian dari alam.

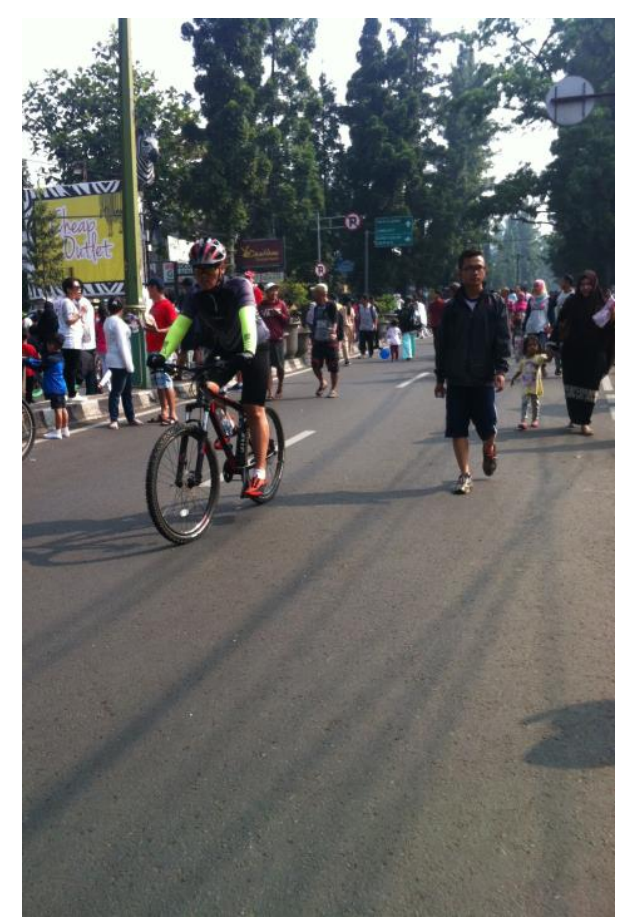

Gambar 1. Menyatu dengan diri yang lain dalam ruang terbuka hijau

Sumber: Dokumentasi Rahayu, 2016

Mengalami ruang seperti ini terasa diri berada di desa, menyatu dalam keterleburan "fourfold"-earth, sky, divinities, mortals-seperti yang diilustrasikan oleh Heidegger (1971). Melebur dengan kesatuan holistik alam; merasakan hembusan angin, menyatu dan membaur dengan diri yang lain, mengalami pengalaman langka sekaligus mengejutkan; saat melihat kebersamaan sepasang kakeknenek dengan becak tuanya.

Ilustrasi kesan di atas adalah bagian pengalaman ruang saat diri berada di kota Bandung. Udara segar yang kian langka di kota, tapi terasa saat berada di ruang-ruang terbuka hijau kota hingga di tempat berlibur daerah perbukitan Lembang, daerah bagian barat Bandung. Kondisi ini persis seperti yang dikatakan oleh Landry (2008), bahwa ide dari kota kreatif itu sendiri berasal dari alasan kaum urban yang tinggal di kota bukan sebagai keinginan melainkan sebagai kebutuhan sehingga ada kerinduan dengan suasana desa. Kerinduan pada alam tanpa asap, kesejukan dan kesegaran angin yang kian langka di ruang kota, seolah terhadirkan di sana.

\section{Penataan Ruang Kota}

Sense of place desa menjadi inspirasi menata infrastruktur kota mulai dari fasos fasum hingga tempat liburan. Kebiasaan orang desa yang cenderung berkumpul, berbincang, bersama, juga dituangkan dalam pembangunan taman-taman di kota Bandung. Taman tematik seperti Taman Jomblo yang sekarang berganti nama menjadi Taman Pasupati di Jl. Balubur, Taman Gesit di Jl. Dipati Ukur, Taman Lansia di Jl. Cilaki, Taman Musik Centrum di Jl. Belitung, Taman Fotografi di Jl. Anggrek, Taman Dago di Jl. Ir. Juanda, Taman Alun-alun yang terletak di pusat kota Bandung, Taman Teras Cikapundung di Jl. Siliwangi merupakan ruang publik di kota yang memungkinkan warga saling berinteraksi. Perjumpaan mereka akan memungkinkan munculnya ide-ide kreatif, gagasan-gagasan baru dan melahirkan banyak komunitas kreatif di Bandung. Cara ini cukup efektif memberikan ruang berkumpul, berbagi dan berdiskusi bagi masyarakat kota di Bandung.

Sense of place desa makin terasa di saat car free day, yang memungkinkan banyak orang saling berinteraksi, dan pasar tumpah seolah menjadi tradisi setiapkali hari minggu tiba. Sensasi pasar desa seperti ini yang kerapkali dirindukan oleh kaum urban. 


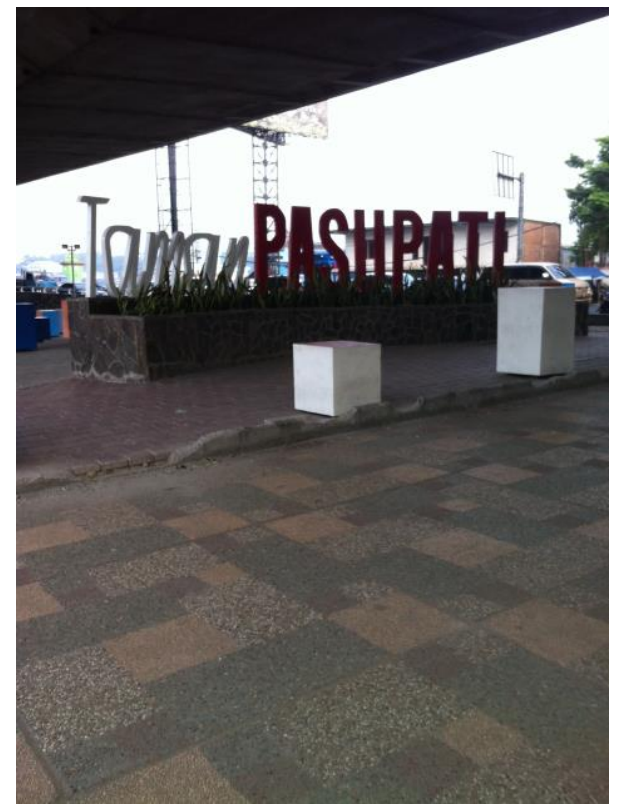

Gambar 2. Taman Pasupati di bawah jembatan layang

Sumber: Dokumentasi Rahayu, 2016

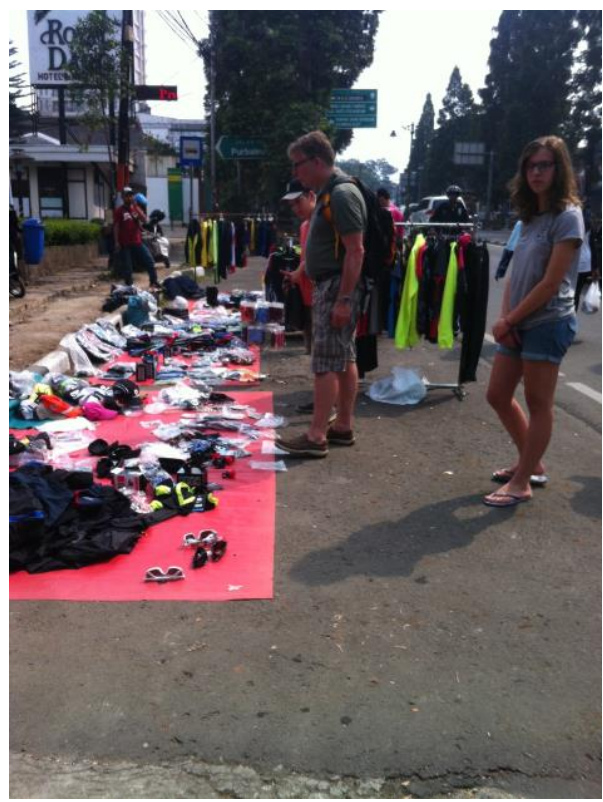

Gambar 3. Pasar tumpah di hari minggu saat car free day

Sumber: Dokumentasi Rahayu, 2016

Car free day memungkinkan suasana bahagia tak terduga, dapat mempererat hubungan, mengenal lebih dekat, mengenal orang baru, memahami orang lain, hingga hanya meluangkan waktu senggang untuk bertemu dan berdiskusi. Ruang-ruang seperti ini sengaja diciptakan untuk warga saling interaksi dan dimungkinkan akan muncul ide-ide kreatif baru yang seringkali tak terduga.

Seperti yang disebutkan oleh Peck (2005) bahwa ekonomi kreatif tidak hanya tentang orang-orang kreatif dan industri kreatif, tetapi juga tentang pemasaran, konsumsi dan pembangunan real estate. Kondisi yang diilustrasikan oleh Peck, juga didapati di kota Bandung. Selain pasar-pasar tradisional di setiap hari dan di moment car free day, Bandung juga mengalami pembangunan yang cukup pesat. Di kawasan sepanjang Jl. Ir. Djuanda, Jl. Cihampelas, Jl. Merdeka, Jl. Ciumbuleuit, J1 Sukarno Hatta, banyak didapati real estate.Tidak hanya itu, pembangunan lainnya terkait dengan fasos fasum juga menjadi perhatian utama pemerintah kota Bandung. Penataan infrastuktur kota mulai dari pembangunan gedung untuk fasilitas umum, akses jalan dan pedestrian, taman-taman kota, saluran air bersih, pemukiman dan perumahan, tempat pembuangan sampah, pengelolaan sampah, sistem drainase, alat transportasi umum juga menjadi perhatian pemerintah. Alat-alat transportasi umum seperti angkot, andong, bus, becak, kereta api, sepeda (bike sharing), dan kuda menjadi pilihan warga.

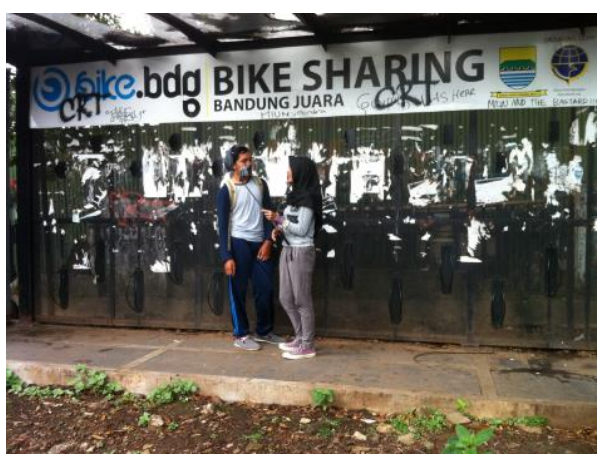

Gambar 4. Bike sharing

Sumber: Dokumentasi Rahayu, 2016 
Kota kreatif tentu memiliki keunikan tersendiri yang berbeda dengan kotakota lainnya. Yang unik di kota ini adalah tersedianya bike sharing yang merupakan solusi untuk mengatasi masalah lingkungan.

Idenya dari Walikota Bandung yang mencoba menggalang komunitas nonprofit sejak 11 November 2011 dan terealisasi pada Juni 2012. Lokasi shelter bike sharing berada di 13 wilayah, dan baru 5 shelter yang aktif (yourbandung.com). Melalui program Bandung bike sharing diharapkan akan meminimalkan polusi, dan menggugah kesadaran warga kota untuk memilih sepeda sebagai alat transportasi yang ramah lingkungan dan menyehatkan. Kini di setiap harinya telah banyak didapati warga yang bersepeda. Ide bike sharing adalah solusi imajinatif yang mengatasi permasalahan polusi dan membuat masyarakat peduli dengan pola hidup sehat.

Tata kota lainnya adalah revitalisasi lapangan Gashibu menjadi: "Gashibu Tepasna Jawa Barat." Proyek ini sedang dalam tahap penyelesaian. Rencananya, akan dibangun menjadi kawasan tempat berkumpulnya orang Bandung.

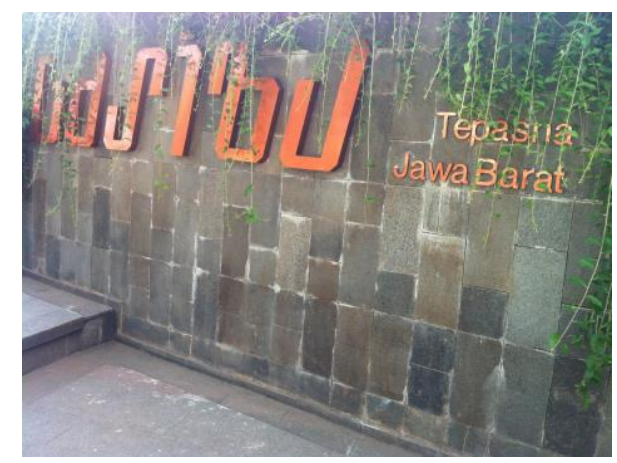

Gambar 5. Gashibu Tepasna Jawa Barat Sumber: Dokumentasi Rahayu, 2016

Sejak menjelang peringatan hari kemerdekaan RI, lapangan tersebut dibuka. Rancangannya mengadopsi budaya Sunda. Berlokasi tepat di depan Gedung Sate, disetiap hari minggu kawasan ini menjadi tempat favorit warga untuk berkumpul, berolah raga, bersepeda, bersantai bersama keluarga dan teman-teman. Sejumlah fitur dan faktor yang membedakan kota kreatif adalah tentang 'keunikan' dan 'keaslian' kota. Menurut Bradford (2004), kota kreatif mengekspresikan keunikan dan keaslian mereka dalam hal: seni, perdagangan, dan masyarakat serta intensitas hubungan diantara ketiga hal tersebut. Keunikan dan keaslian budaya lokal dengan ciri berkumpul (ngariung)menjadi potensi yang memungkinkan terbentuknya ideide kreatif.

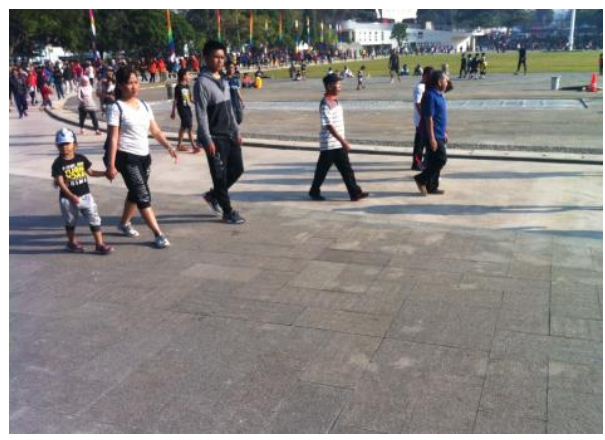

\section{Gambar 6. Ruang bersama di lapangan Gashibu hari minggu \\ Sumber: Dokumentasi Rahayu, 2016}

Mengitari lapangan Gashibu sambil menggerakkan tubuh dengan pancaran sinar matahari pagi, tentu akan membuat masyarakat menjadi lebih sehat. Hal ini akan meminimalkan angka kematian sekaligus juga dapat menjaga hubungan dengan orang terdekat yang disetiap harinya waktu habis untuk kerja. Tahap berikutnya Gashibu Tepasna Jawa Baratjuga akan dilengkapi dengan taman, area parkir sepeda, galeri para seniman Jawa Barat dan amphitheater.Kata "Tepasna" dalam kalimat "Bandung Tepasna Jawa Barat"mengindikansikan pemberdayaan lokalitas dalam penataan infrastruktur kota. Hal ini 
sesuai dengan syarat yang diajukan oleh Landry (2008: 36, 204) tentang kota kreatif, salah satunya mengkondisikan sense of locality dalam penataan kota. Ini yang akan menjadi sentuhan unik, sebagai identitas kota tersebut yang berbeda dengan kota lainya.

Apa yang dilakukan pemerintah kota Bandung dalam merevitalisasi kawasan Gashibu, senada dengan gagasan UNCTAD (2008), bahwa kota kreatif menggunakan potensi kreatif mereka dalam berbagai cara melalui pertunjukan dan seni rupa, beberapa festival yang membentuk identitas dan strategi pemasaran kota lewat industri budaya untuk menyediakan lapangan kerja dan pendapatan. Jika kita perhatikan, program yang digagas dan diwujudkan menjadi kota kreatif di Bandung sebenarnya mengacu pada Rencana Tata Ruang Wilayah Kota Bandung, sesuai PERDA No. 18 Tahun 2011-2031, Pasal 32, yang berbunyi: "Struktur ruang adalah susunan pemukiman dan sistem jaringan prasarana dan sarana yang berfungsi sebagai pendukung kegiatan sosial ekonomi masyarakat yang secara hierarkis memiliki hubungan fungsional."

Tata ruang lainnya yang juga menjadi perhatian pemkot Bandung adalah revitalisasi bangunan-bangunan heritage seperti: Alun-alun dan Gedung Merdeka yang berlokasi di Jl. Asia Afrika, bangunan bersejarah di $\mathrm{Jl}$. Braga, dan Gedung Sate di Jl. Diponegoro. Pembangunan di sepanjang Jl. Asia Afrika menjadi kawasan wisata yang menarik untuk dikunjungi di pusat kota Bandung. Bangunan-bangunan bergaya Art Deco dengan beragam kisah sejarah dapat ditelusuri di sepanjang jalan. Tepat di kawasan Jl. Braga dan Jl. Asia Afrika didapati gedung-gedung bangunan tua yang masih berfungsi hingga sekarang. Museum Konferensi Asia Afrika yang menyatu dengan Gedung Merdeka adalah salah satunya.

Dulu gedung ini dikenal dengan nama Societeit Concordia yang dikenal dengan tempat berkumpulnya masyarakat kota Bandung untuk kalangan atas. Seiring berkembangnya zaman, gedung tersebut beralih fungsi sebagai tempat pertemuan Konferensi Asia Afrika (KAA) dan sejak tahun 1980 berganti nama menjadi Museum Asia Afrika (direktori-wisata.com).

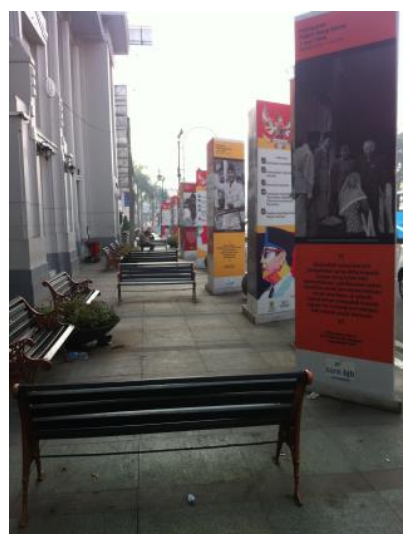

Gambar 7. Penataan trotoar di sepanjang Jl. Asia Afrika

Sumber: Dokumentasi Rahayu, 2016

Trotoar di sepanjang Jl. Asia Afrika ditata dengan gaya Eropa untuk mengenang Bandung Tempo Doeloe. Bangku-bangku diletakkan disepanjang jalan, batu berbentuk bola besar bertuliskan nama-nama Negara perserta KAA, umbul-umbul bergambar dan bertuliskan sejarah KAA, dan tepat di pertigaan Jl. Asia Afrika didapati monument bertuliskan nama-nama Negara peserta KAA.

Tata kota di Bandung yang peduli pada nilai sejarah masa lalu-seperti konsentrasi pemkot pada bangunan heritage di Jl. Asia Afrika, Jl. Braga dan Jl. Diponegoro tersebut sebenarnya 
sesuai dengan konsep kota kreatif yang digagas oleh Landry (2008). Menurutnya gagasan kota kreatif dari formula aslinya berfokus pada potensi industri budaya, seperti yang terlihat bahwa kota harus berkonsentrasi pada apa yang mereka perbuat dan khusus. Dalam konteks ini, proyek-proyek seni dan pemeliharaan bangunan tua bersejarah tentu sangat signifikan untuk menjadikan Bandung sebagai kota kreatif.

Menjadi kreatif bukan berarti hanya peduli pada yang baru, melainkan juga apa upaya untuk meninjau dan menilai kembali semua situasi dengan cara yang fleksibel (Landry, 2008). Perlu keberanian untuk perubahan jika diperlukan dan memiliki penilaian yang baik untuk menjaga sejarah. Oleh karena itu sejarah dan kreativitas menjadi kombinasi yang menarik antara budaya lama dan baru. Kreativitas adalah upaya untuk mengeksplorasi sumber daya dan membantu mereka untuk tumbuh. Tugas perancang kota adalah mengenali, menggali, mengelola dan mengembangkan sumber daya secara bertanggung jawab.

\section{Strategi Perencanaan Menuju Kota Kreatif}

Landry (2008) melihat kota kreatif identik dengan kota yang memiliki kreativitas sumber daya manusia dan industri budaya dengan keunikan dan kekhasannya. Namun di kota kreatif, bukan hanya seniman dan mereka yang terlibat dalam 'ekonomi kreatif' yang kreatif, meskipun mereka memainkan peran penting. Lebih jauh Landry (2008) mengatakan bahwa menjadi kreatif berarti memiliki kemampuan untuk berpikir sesuatu yang berbeda, memiliki ketertarikan untuk belajar sesuatu yang baru, melihat hubungan yang yang tidak biasa, tidak takut dengan keambiguan, paradox atau kontradiksi, dan mencipta sesuatu yang original. Yang menarik dari pernyataan Landry (2008) adalah bahwa dalam kota kreatif bukan berarti selalu terkondisi untuk mencipta kebaruan, melainkan juga terbiasa untuk melihat situasi dengan cara yang fleksibel; jika mungkin mengangkat budaya lama dengan cara yang kreatif.

Dalam konfigurasi kawasan kota, 'keativitas merupakan salah satu mata uang utama (Landry, 2008). Kota kreatif tentu memiliki kebijakan dan strategi perencanaan yang tidak jauh dari kata 'kreatif', 'imajinatif', dan 'inovatif.'Kreativitas lahir karena kuriositas yang membuka pikiran dan mencari wawasan serta kemungkinankemungkinan baru menghadapi masalah kota. Problem kemacetan, misalnya, dapat diatasi dengan ajakan naik bus ("ayo naik bus")dan angkot gaul sebagai transportasi umum.Sedangkan problem polusi dapat diatasi dengan ajakan naik sepeda lewat program "bike sharing. "Imajinasi diperlukan untuk membuat lompatan-lompatan ide, melihat koneksi yang tidak biasa, mencipta keambiguan bahkan keganjilan. Seperti upaya mengatasi problem kemacetan dan upaya menjajakan kuliner, bisa diatasi lewat bus kuliner keliling kota Bandung. Juga bagaimana mengatasi kemacetan sekaligus mempromosikan kota Bandung sebagai destinasi wisata, disiasati dengan pengadaan "Banros" (bus wisata kota).

Strategi perencanaan Walikota Bandung tentang kota kreatif, dapat kita lihat dari 7 point dalam membenahi kota, diantaranya:

1. Membuat bus sekolah gratis. Kini bus yang menampung 70 orang tersebut sudah beroperasi. 
Rancangannya unik dan fun sebagai representasi dunia anak sekolah. Tujuannya adalah mengurangi kemacetan dan biaya sekolah.

2. Membuat taman tematik. Udara Bandung yang sejuk, akan terasa jika banyak ruang terbuka hijau.

3. Bandung bebas dari asap rokok. Program ini untuk meminimalkan polusi udara di kota Bandung. Melalui program Selasa Tanpa Asap Rokok, diharapkan warga Bandung sadar akan kesehatan pribadi dan lingkungan.

4. Parkir modern dengan sistem pra bayar. Program tersebut sudah diterapkan di Jl. Braga, dengan sistem operasional: Rp.2000,- untuk jam pertama, dan Rp.2000,- untuk jam selanjutnya.

5. Menjadikan Jl. Braga sebagai pusat kuliner Bandung. Program ini digelar setiap malam minggu, pukul 18.00-02.00 WIB, dengan menu sajian mulai dari kelas bawah sampai kelas atas.

6. Bandung terkoneksi internet. Melalui program Bandung terkoneksi internet yang dapat diakses di taman-taman kota, gedung pemerintahan kota hingga desa, Walikota Bandung berencana menjadikan Bandung sebagai Smart City. Hal ini akan mempermudah segala urusan pemerintahan dan jaringan dengan warga.

7. Bus tingkat Bandung Tour On Bus. Diharapkan melalui program ini wisatawan luar kota tidak lagi mengitari Bandung dengan mobil pribadinya yang membuat kemacetan lalu lintas (merdeka.com).

Program-program pemerintah tersebut mengindikasikan terbentuknya kota kreatif di Bandung. Kiranya jelas bahwa ruang-ruang kreatif merupakan faktor utama pembentuk kota kreatif. Lebih detail lagi Landry dan Hyams (2012), mengajukan syarat bahwa kota kreatif ditentutan oleh beberapa faktor, diantaranya: (1) adanya ruang-ruang kreatif di berbagai sudut kota, (2) adanya kesadaran untuk mengeksperikan ide kreatif dari kalangan terdidik, (3) adanya pimpinan dan kebijakan yang memberi ruang untuk mengembangkan berbagai industri kreatif, (4) adanya pengaturan wilayah, toleransi dan aksesibilitas termasuk bagaimana agar para warga dapat melakukan perjalanan mudah, murah dan nyaman. Syarat-syarat tersebut memang didapati di kota Bandung.

Ruang-ruang kreatif bertebaran di sudut kota Bandung dalam komunitas kampung-kampung kreatif. Kampung kota menjadi semacam kolase mini warga kota yang memungkinkan mereka untuk terus mengembangkan prinsip-prinsip toleransi, keragaman, dan kesetiakawanan. Hal ini tampak dalam ungkapan graffiti mural di Kampung Kreatif Dago Pojok bertuliskan:

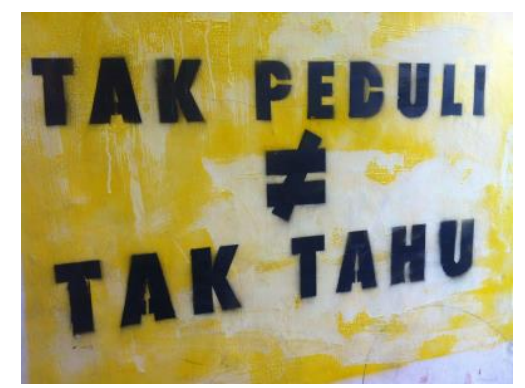

\section{Gambar 8. Ungkapan sindiran tentang ketidakpedulian}

Sumber: Dokumentasi Rahayu, 2016

Karya seni memang lebih jujur mengatakan yang tak terkatakan. Seni dapat mendidik hati dan mempertajam rasa. Pesan-pesan, himbauan, teriakan, atau bahkan kritikan seringkali lebih dapat tersampaikan melalui olah bentuk 
seni yang unik tak terduga. Seni mengatakan kebenaran yang kerap tersembunyi dan tak terperhatikan. Kreativitas warga tentu tidak akan pernah ada jika tanpa dukungan pemangku kebijakan kota. Walikota Bandung, yang juga seorang arsitek dengan gagasan kreatifnya kiranya menjadi pemicu untuk mewujudkan kota kreatif dengan menggali kreativitas warga kota. Banyak hal telah dilakukan, mulai perbaikan infrastruktur kota, penyediaan sarana dan prasarana, pengembangan kampung kreatif yang semua itu melibatkan peran aktif warga.

\section{Peran Masyarakat}

Konsep kota kreatif yang dikembangkan oleh Landry di akhir tahun 1980 dan studi tentang The Creative City: A Tollkit for Urban Inovators di tahun 2008 telah menjadi dokumen acuan utama kota kreatif. Filosofi kota kreatif Landry didasarkan pada imajinasi orang dan ia menggambarkan kota kreatif sebagai 'tempat di mana orang berpikir, berencana, dan bertindak dengan imajinasi.

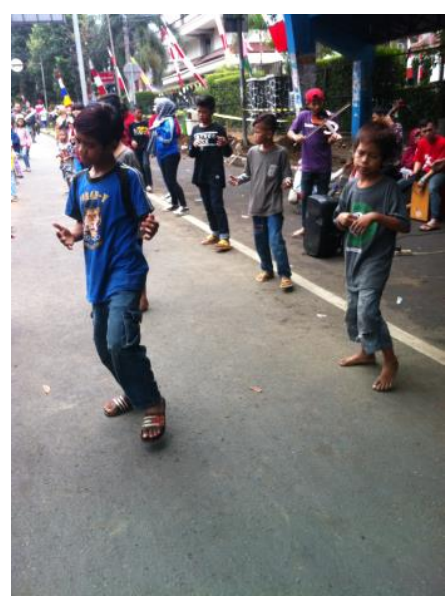

Gambar 9. Kepolosan anak-anak saat menari dengan iringan musik

Sumber: Dokumentasi Rahayu, 2016

Landry (2008) mengatakan bahwa masyarakat adalah faktor yang sangat penting dari kota. Kota kreatif membutuhkan masyarakat yang cerdas, memiliki kehendak, motivasi, imajinasi dan kreativitas. Kreativitas seringkali muncul dalam kondisi ketika tidak berada dalam zona nyaman. Kondisi Bandung yang tidak memiliki sumber daya energi, telah menuntut mereka berpikir kreatif dan inovatif.

Masyarakat Bandung dari anak-anak hingga orang dewasa, mereka cenderung berani berekspresi. Itu sebabnya banyak bermunculan seniman dan kelompok kreatif lainnya. Gagasan Florida (2002) tentang adanya kelas kreatif menghubungkan pada ide tentang kota kreatif, yang sekaligus menjadi aspek penting didalamnya. Kelompok masyarakat yang termasuk dalam kelas kreatif adalah desainer, arsitek, ilmuwan, seniman dan pemikir. Sementara itu paradigma kreativitas kota juga terhubung dengan gagasan ekonomi kreatif.

Selain adanya kampung kreatif, warga Bandung banyak yang mengasah kreativitas dari pengalamannya sewaktu kuliah dengan membuat: sepatu lukis, kaos lukis, hingga berbisnis kuliner. Kedasaran ini tentu menjadi modal utama pembentukan kota kreatif. Seperti yang dilakukan oleh kelompok kreatif di bidang desain kaos di kota Bandung yang menjajakan informasi seputar kota Bandung. Konsep ini juga menjadi konsentrasi kota kreatif yang digagas oleh Landry (2008), bahwa pada intinya ada tiga domain untuk mengembangkan ekonomi kreatif: industri media dan hiburan, seni dan warisan budaya, dan layanan kreatif bisnis-ke-bisnis.

Girard, L.F., Baycan, T., Nijkampt. P. (2011) mengklasifikasikan bahwa kota kreatif memiliki kriteria mendasar yang mempertimbangkan faktor ekonomi, 
sosial, lingkungan dan budaya. Keempat faktor tersebut tidak bisa berdiri sendiri, atau lebih mendominasi satu dari yang lainnya, melainkan saling bersinergi membentuk kesatuan kota kreatif. Seperti peningkatan ekonomi dari sektor pemberdayaan lokalitas, sekaligus menjadi peluang peningkatan kesejahteraan sosial, pembangunan berbasis lingkungan dan pelestarian budaya lokal.Kota Bandung, mencoba menggalakkan sektor industri lokal menjadi industri kreatif.

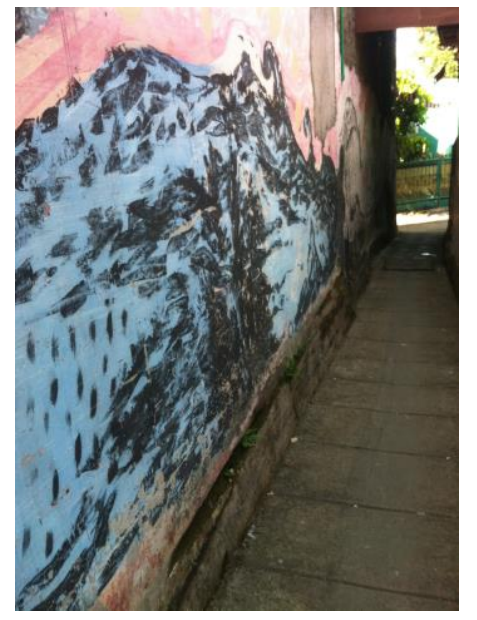

Gambar 10. Gang jalan masuk ke kampung kreatif di Dago Pojok

Sumber: Dokumentasi Rahayu, 2016

Lukisan mural di lorong ruang kampung kreatif adalah sisi lain dari tampang wajah kota Bandung. Kedepannya kampung kreatif di Dago ini menggalakkan industri fashion berbasis seni lukis. Peran serta masyarakat kota Bandung juga banyak dari para pengusaha batik yang mengusung lokalitas Jawa Barat. Salah satunya adalah Wisata Batik Komar, yang berlokasi di Jl. Cigadung dan Jl. Sumbawa. Selain menjajakan ragam batik yang kaya warna dengan corak tradisi dan urban modern, juga menyelenggarakan kursus/ pelatihan membatik, dan proses pencelupan/ pewarnaan.

\section{Strategi Berkelanjutan}

Predikat sebagai kota kreatif bagi Bandung yang disematkan oleh UNESCO di bidang desain tahun 2015, kiranya makin memperkuat komitmen Walikota Bandung untuk menggalakkan program ekonomi kreatif melalui smart city. Ditambah lagi dukungan Presiden RI, Jokowi melalui Badan Ekonomi Kreatif yang menyiapkan Bandung dan Yogyakarta sebagai kota kreatif di Indonesia (detikNews, 2015). Terkait dengan hal ini, Walikota Bandung merencanakan strategi berkelanjutan melalui beberapa program penggalakan ekonomi kreatif diantaranya:

1. Industri fashion. Selain adanya factory outlet di sepanjang $\mathrm{Jl}$. Ir.Juanda, kawasan Dago yang menjadikan kota ini terkenal dengan kota fashion, juga didapati wisata Batik Komar yang mengusung konsep educative, creative learning \& shopping dalam Brosur Batik Komar, 2016.

2. Industri desain. Bandung terkenal dengan sebutan kota mode, dan ini yang menjadikan desain pakaian yang diproduksi masyarakat Bandung terbilang cukup unik dan menarik.

3. Industri IT (information technology). Melalui program Bandung terkoneksi internet, masyarakat industri kreatif teknologi dan komunikasi Indonesia (MIKTI) bekerjasama dengan Telkom telah mendirikan Lembah Digital Bandung (Bandung Digital Valley/ $B D V)$ yang difokuskan untuk mengembangkan industri IT local.

4. Industri kuliner. Pesatnya bisnis kuliner di Bandung, sebagian dari pelaku bisnis kuliner mulai membentuk komunitas pengusaha yang diberi nama Sindikat Kuliner. 
Selain kawasan Dago sebagai sentra fashion, kawasan lainnya di Bandung juga menjadi kawasan ekonomi kreatif; misalnya: Cibaduyut sebagai sentra industri sepatu kulit, Cibuntu sebagai sentra industri tahu, Sukamulya Sukaja sebagai sentra industri boneka, Binongjat sebagai sentra industri dan perdagangan, Cigondewah sebagai sentra produksi dan perdagangan kain, Cihampelas sebagai sentra perdagangan jeans, Suci sebagai sentra industri sablon dan kaos.

Jika kita perhatikan, upaya pemkot Bandung menggalakkan program ekonomi kreatif memang beralasan, karena komunitas-komunitas kreatif merupakan roda penggerak ekonomi kota. Berdasarkan survey tahun 2011, kota Bandung termasuk dalam jajaran 5 besar kota kreatif se-Asia. Saat ini di kota Bandung sudah ada 400 outlet industri kreatif dan dapat menyerap kurang lebih 334.244 tenaga kerja. Secara regional, pada tahun 2012 kontribusi ekonomi kreatif kota Bandung terhadap produk domestic regional bruto (PDRB) provinsi Jawa Barat, hampir $8 \%$ atau sekitar 21 triliun dan telah menyerap tenaga kerja sekitar $2,75 \%$ dari jumlah total tenaga kerja. Kontribusi terbesar ekonomi kreatif di kota Bandung diberikan di bidang desain, fashion, kerajinan, kuliner dan turisme (Koran Sindo, 2015).

Tidak hanya kampung kreatif yang berada di perkotaan, tetapi di daerah perbukitan Lembang juga menjadi kawasan wisata yang menjajakan tempat kuliner, edukasi, sekaligus rekreasi. Konsepnya hampir serupa, yaitu mengusung lokalitas budaya Sunda Kampung Naga ke dalam perancangan arsitektur Kampung Layung. Selain itu spot dengan nuansa kampung, juga didapati spot-spot yang memfasilitasi para pebisnis kuliner dan pengrajin dapat menjajakan makanan khas dari berbagai daerah di Indonesia.

Strategi yang dilakukan Walikota Bandung dalam membangun kota, yaitu: inovasi, desentralisasi, dan kolaborasi (Bappenas.go.id). Pertama, inovasi maksudnya adalah adanya upaya untuk mengubah gaya hidup dan perilaku masyarakat agar menjadi lebih sopan, santun, tertib, bahagia, yang didorong oleh leadership dan tata kelola yang baik. Kedua, desentralisasi mengupayakan adanya distribusi kewenangan dari Walikota ke Lurah, RT/RW, Karang Taruna, PKK, dan lembaga pemberdayaan masyarakat lainnya. Ketiga, kolaborasi/ kerjasama dengan berbagai pihak, antara lain: akademia, pengusaha, komunitas, dan institusi.

\section{Kesimpulan}

Penjelasan di atas sekaligus mempertegas bahwa upaya menuju Bandung Kota Kreatif dilakukan melalui pemberdayaan 'ekonomi kreatif' di bidang fashion, kuliner, dan desain yang bertebaran menghiasi wajah kota hingga wilayah perbukitan. Hal lain yang tak terduga adalah kondisi kota kreatif di Bandung memungkinkan pencapaian masyarakat hidup sejahtera dan mandiri secara ekonomi. Melalui program 'Bandung Kota Kreatif', imbasnya bukan hanya menuju kota kreatif tapi sebagai 'smart city' yang dilakukan melalui strategi: inovasi, desentralisasi dan kolaborasi. Kondisi yang terjadi di kota Bandung yang telah dinobatkan sebagai kota kreatif oleh UNESCO sebenarnya merepresentasikan gagasan pada pemikir "kota kreatif" sebelumnya. Itu sebabnya Bandung menjadi salah satu kota kreatif karena upaya pembayaan lokalitas dan kreativitas masyarakat 
setempat juga dukungan pemerintah kota yang menjelma dalam penataan insfatruktur.

\section{Daftar Pustaka}

Bradford, N. (2004). Creative cities structured policy dialogue backgrounder, $\quad C P R N$ (Canadian Policy Research Networks), Paper F/46, August 2004.

Batik Komar: Wisata Batik Educative, Creative Learning \& Shopping (Brochure). Bandung: Rumah Batik Komar.

Bandung Kota Kreatif Dunia UNESCO. (15 Desember 2015). Koran Sindo.

Creswell, J.W. (2008). Research design: Qualitative, quantitative, and mixed methods approaches. Second Edition London: Sage Publications, Inc.

Florida, R. (2002). The rice of the creative class - and how it is transforming leisure, community and everyday life. New York: Basic Book.

Gabe, T.M. (2006). Growth of creative occupations. U.S: Metropolitan Areas Growth and Change, 37 (3). P. 369-415.

Girard, L.F., Baycan, T., Nijkamp, P. (2011). Sustainable city and creativity promoting creative urban initiatives, UK, England: Ashgate, p. xxv.

Harris, A., Moreno, L. (2011).Creative city limits, Art and humanities research Concil, UK, Urban Lab, UCL Urban Laboratory.

Heidegger, M. (1971). Poetically man dwells, in Poetry, language, thought, trans. By. Hofstadter, Albert. New York: Harper \& Row.
Helbrecht, I. ed. (2004). Bare gographies in knowledge societies -creative cities as text and piece of art: Two eyes, one vision. Built Environment, 30 (3), 194-203.

Hall, P. (1998). Cities in civilization. London: Weidenfeld and Nicolson.

Hall, P. (2000). Creative cities and economic development. Urban Studies. 37 (4), 639-49.

Heilbrun, J., Gray, C.M. (1993). The economics of art and culture, UK: Cambridge University Press.

Howkins, J. (2002). The creative economy: How people make money from ideas. Harmondsworth: Penguin.

ISoCaRP. (2005). Making Spaces for The Creative Economy.

Jones, T. (2007). Cultural districts. HKIP and UPSC Conference: When creative industries crossover with cities. Hong Kong, 2-3 April.

Landry, C. (2008). The creative city: A toolkit for urban innovation. Second Edition. London. Sterling, VA: Comedia Earthscan,

Landry, C., Hyams, J. (2012). The creative city index: Measuring the pulse of the city, $\mathrm{UK}$ : Comedia.

Musterd, S., Bonthe, M., Chapain, C., Kovacs, Z., Murie, A. (2007). Accomodating creative knowledge: A literature review from a european perspective. ACRE Report 1. Amsterdam: AMIDSt.

Peck. J. (2005). Struggling with the creative class. International Journal of Urban and Regional Research. 294, 740-70. 
Peraturan Daerah Kota Bandung No.

18 Tahun 2011. Tentang:

Rencana Tata Ruang Wilayah

Kota Bandung Tahun 2011-

2031. Kota Bandung. Lembaran

Daerah Kota Bandung.

Pratt, A. (1997). The cultural industries production

system.

Environment and Planning. A, 29, 1953-74.

Scott, A. (2000), The cultural economy of paris. International Jornal of Urban and Regional Research. 24, 567-82.

Scott, A. (2003). The cultural economy of cities. London: Stage.

UNCTAD. (2008). The challenge of assessing the creative economy: Toward informed policymaking. Creative Economy Report 2008. United Nations. UNCTAD/DITC/2008/2.

Wu, W. (2005). Dynamic cities and creative clusters. World Bank Policy Research Working Paper. 3509. 